\title{
Erratum to: Special Aspects of the Development of Health Information Systems as One of the Areas of Expertise of University Students Majoring in Professional Instrument Engineering
}

\author{
Elena Vaganova ${ }^{1,2}$ \\ ${ }^{1}$ Diagnostika + LLC, 634055, Tomsk, Russia \\ ${ }^{2}$ National Research Tomsk State University, 634050, Tomsk, Russia
}

Original article:

MATEC Web of Conferences 79, 01057 (2016), DOI: 10.1051/matecconf/20167901057

1. One affiliation must be added: Diagnostika + LLC , 634055, Tomsk, Russia

2. In the section Acknowledgement, the line ", and the program of improving competitiveness of the TSU (project No. 8.2.31.2015)" must be deleted. 